\title{
THE FATE OF SMECTITE IN KOH SOLUTIONS
}

\author{
A. Bauer ${ }^{1}$, B. Lanson ${ }^{2}$, K. Emmerich ${ }^{3}$, E. Ferrage ${ }^{2}$, H. Taubald ${ }^{4}$, \\ D. Schild ${ }^{1}$, B.Velde
}

Forschungszentrum Karlsruhe, Institut für Nukleare Entsorgung, PO Box 3640, 76021

Karlsruhe, Germany

Environmental Geochemistry Group, L.G.I.T. - Maison des Géosciences, Université J.

Fourier, B.P. 53, 38041 Grenoble Cedex 9, France

3 FZK-ITC-WGT, PO Box 3640, 76021 Karlsruhe, Germany

$4 \quad$ Universität Tübingen, Institut für Geowissenschaften, AB Mineralogie und

Geodynamik, Lehrstuhl für Geochemie, Wilhelmstr. 56, 72074 Tübingen, Germany

5 Ecole Normale Supérieure, Département de Géologie, 24, rue Lhomond, 75231 Paris

Cedex 05, France 


\section{Abstract}

The aim of the present study was to investigate the detailed evolution of the SAz-1 smectite in $1 \mathrm{M} \mathrm{KOH}$ at $80^{\circ} \mathrm{C}$ at a solid/liquid ratio of $1 / 80$. AFM observations indicated no change in crystal size or shape. XRD measurements at $40 \%$ relative humidity revealed changes in expandability of the smectite. The 001 reflection profile of smectite was modelled using the trial-and-error approach of Sakharov et al., 1999b. The results indicate that with increasing run time the number of non expandable layers with zero or one water layer increases and that the coherent scattering domain size of the smectite decreases. Infrared spectroscopy of the reacted smectite suggests that there is no change from the initial clay products. The dehydroxylation temperature showed a slight decrease from $619^{\circ}$ to $605^{\circ} \mathrm{C}$. STA measurements demonstrated that the cis-vacant character of the octahedral sheet remained nearly unchanged throughout the experiment. Determination of the average layer charge showed a continuous increase from 0.32 to $0.42 \mathrm{eq} / \mathrm{Si}(\mathrm{Si} / \mathrm{Al})_{4} \mathrm{O}_{10}$ whereas the layer charge distribution indicated the appearance of high charged smectite layers with a charge of $\sim 0.6$ eq/Si $(\mathrm{Si} / \mathrm{Al})_{4} \mathrm{O}_{10}$ and the disappearance of the low charged layers. XPS and SEM measurements indicate an increase of the aluminium in the smectite samples. Isotope data support the theory of a internal diffusion mechanism by gradual changes in $\delta^{18} \mathrm{O}$ values.

From these data it appears that $\mathrm{KOH}$ solutions provoke a mineralogical change in the 2:1 layer of the smectite minerals which increases the layer charge by increasing the Al content. This mineralogical change does not involve dissolution/crystallization processes and then must show solid state transformation of the clays at $80^{\circ} \mathrm{C}$. 


\section{Introduction}

In 1997 at the end of a workshop dedicated to Victor Drits by the French Clay Group Bernard Kübler proposed that it would be a great help if the speakers would give their definitions of vermiculite, high-charge-smectite and illite at the beginning of their talks. As a matter of fact a look through literature reveals that the terms used for expandable layers in the smectite to illite reaction are just operationally defined and as such they do not necessarily coincide with definitions from the Nomenclature committee of the AIPEA. The aim of our study was to investigate the fate of smectite during a possible smectite to illite transformation. The question is then, is smectite just a passive partner in the reaction giving the ingredients for the new phase illite or is illite perhaps smectite with a higher charge and smectite collapse occurs only when potassium is supplied to the high-charge interlayer sites?

Chemical compositions of diagenetically altered shales, sandstones or bentonites studied by Srodon et al., 1992; Srodon et al., 1986, Nadeau and Bain, 1986, Awwiller, 1993 and Cuadros and Altaner, 1998 indicate the formation of high-charge expandable layers together with the illitization process. The experimental illitization of smectite indicates the proportion of highcharge layers increases followed by the potassium fixation and the subsequent illitization (Whitney and Northrop, 1988). These high-charge but exchangeable layers are comparable to the vermiculitic component described by Shutov et al., 1969 and Drits et al., 1997a. As a result, a randomly interstratified illite/smectite (R0 I/S) mixed-layer structure (MLS) has three components: one fully expandable (smectite), one partially expandable (vermiculite) and one non expandable (illite). This means that the smectite-to-illite transformation must involve the vermiculitization of the smectite layers through the formation of high-charge, tetrahedrallysubstituted layers from the original clay (Drits, 1985). Meunier et al., 2000 described this process as the vermiculitization of smectite interfaces. In their model the low-charge 
montmorillonite is transformed into a high-charge vermiculite which remains partly expandable (one water layer or one ethylene glycol layer at $80 \%$ relative humidity) if the interlayer is not $\mathrm{K}^{+}$- or $\mathrm{NH}_{4}{ }^{+}$-saturated. A vermiculite interlayer leads to the formation of illite when $\mathrm{K}$ or $\mathrm{NH}_{4}^{+}$is supplied. But how are smectite particles transformed during their transition to R0 I/S? Two processes may control the reaction by solid state transformation (Dunoyer de Segonzac, 1970 Hower et al., 1976) or dissolution/crystallisation (Baronnet, 1997, Altaner and Ylagan, 1997). Many studies have reported evidence supporting one or the other reaction mechanism.

In the literature two experimental pathways are commonly used to obtain illite from a smectite precursor. One is to use $\mathrm{KCl}$ and high temperatures $\left(>200^{\circ} \mathrm{C}\right)$ and pressures and the other is to use $\mathrm{KOH}$ at low temperatures $\left(<100^{\circ} \mathrm{C}\right)$. Hydrothermal synthesis experiments have formed R0 I-S from smectite at elevated temperatures (e.g. Robertson and Lahann, 1981, Whitney and Northrop, 1988). Reactions in $\mathrm{KOH}$ solutions lead to the decrease of the coherent scattering domain size of the smectite followed by the illitization of the smectite and finally the formation of pure illite (e. g. Eberl et al., 1986, Eberl et al., 1993, Bauer and Velde, 1999). In the present study we focus on the $\mathrm{KOH}$ system. The aim of the present manuscript is to follow the fate of a fully expandable and low-charge smectite before it becomes illite in $\mathrm{KOH}$ solutions with different experimental techniques.

\section{Materials and Methods}

Starting Clay: The starting clay mineral for this experimental study was purified homoionic montmorillonite obtained from the SAz-1 source clay material (Clay Minerals Society, Purdue University, http://www.clays.org/sourceclays/SourceClays.html). In a first step the clay was conditioned to remove soluble salts, sparingly soluble minerals and trace cation 
impurities after the procedure proposed by Bauer and Velde, 1999. The purified smectite was converted into its sodium form (Moore and Reynolds, 1997) and the $<1 \mu \mathrm{m}$ fraction of smectite was separated by sedimentation techniques (Day, 1965). XRD analysis for conditioned clay revealed that montmorillonite is present at $100 \%$. Finally the clay separate was converted into its potassium form.

Starting solution: The solutions were prepared from analytical grade chemicals. A Milli-Q Reagent Water System from Millipore Corp. provided deionized water (DI) with a resistivity of $>18 \mathrm{M} \Omega \mathrm{cm}^{-1}$.

Experimental protocol: Smectite samples weighing $2 \mathrm{~g}$ were added to $160 \mathrm{ml}$ of $1 \mathrm{M} \mathrm{KOH}$ aqueous solution. Reactions were conducted in HDPE Nalgene bottles kept in ovens at $80^{\circ} \mathrm{C}$ with reaction times lasting up to 150 days. The bottles were shaken twice a week. At the end of an experimental run the bottles were removed, quenched in cold water $\left(25^{\circ} \mathrm{C}\right)$ and opened. The supernatant was filtered through a $0.1 \mu \mathrm{m}$ Nucleopore membrane into cleaned polypropylene bottles and analysed. The solid material was then washed carefully five times with $150 \mathrm{ml}$ of DI water. After washing the material, it was five times resuspended for 1 minute in a ultrasonic bath in $150 \mathrm{ml}$ of $1 \mathrm{M} \mathrm{SrCl}_{2}$ solution. Saturation with $\mathrm{Sr}^{2+}$ was used to ensure the presence of two water layers in the expandable layers under XRD data collection conditions (see below). To promote complete cation exchange, the suspensions were stored after the ultrasonic treatment for $4 \mathrm{~h}$ at $50^{\circ} \mathrm{C}$. After this procedure the sample was washed five times with $150 \mathrm{ml}$ of DI water. After washing the samples one part of the solid was used to prepare the XRD slide while the other rest was converted into the sodium form and freeze dried for layer charge measurements, oxygen isotope and XPS measurements as well as for thermal analysis. 
X-ray diffraction: The evolution of clay mineral structure and the formation of secondary phases were monitored by XRD. Oriented slides were prepared by pipetting a slurry of Srsaturated samples on a glass slide and drying it at room temperature for a few hours to obtain an air-dried preparation. XRD scans were recorded on a Bruker D5000 diffractometer $(\mathrm{Cu}$ radiation at $40 \mathrm{kV}$ and $40 \mathrm{~mA}$ ) equipped with an Ansyco rh-plus 2250 humidity control device coupled to an Anton Paar TTK450 chamber. The measuring range was from $2^{\circ}$ to $50^{\circ} 2 \theta$ with a step size of $0.04^{\circ}$ and 6 second counting time. The divergence slit, the two Soller slits, the antiscatter slit and the resolution slit were $0.5^{\circ}, 2.3^{\circ}, 2.3^{\circ}, 0.5^{\circ}$ and $0.06^{\circ}$, respectively. All XRD analyses were conducted at a relative humidity of $40 \%$ after an homogenisation period of about $15 \mathrm{~min}$ before the measurement.

The 001 reflection profile of SAz-1 smectite was modelled using the algorithms developed initially by Sakharov and Drits, 1973, Drits and Sakharov, 1976, Drits et al., 1997a, Sakharov et al., 1999a. In addition, smectite hydration heterogeneity was monitored using the methodology developed by Ferrage, 2005a. This heterogeneity results from the coexistence in the same crystal of the different layer types usually considered in smectite structure in nonsaturated water vapour conditions: dehydrated layers (0W layers, layer thickness at 9.610.1 $\AA$ ), mono-hydrated layers with one plane of $\mathrm{H}_{2} \mathrm{O}$ molecules in the interlayer (1W layers at 12.3-12.7 $\AA$ ), and bi-hydrated layers with two planes of $\mathrm{H}_{2} \mathrm{O}$ molecules in the interlayer (2W layers at 15.1-15.8 $\AA$ ). Such structural heterogeneity can be seen as the result of both contrasted layer charges from one layer to the other or within a single layer and intrinsic thermodynamic effects.

For the modelling of all experimental XRD pattern, the preferred orientation of the sample $\left(\sigma^{*}\right)$ was set to $7^{\circ}$. Because the water content of hydrated layers cannot be determined accurately from the sole 001 reflection, the number of $\mathrm{H}_{2} \mathrm{O}$ molecules was set to 3 and 6 
$\mathrm{H}_{2} \mathrm{O} / \mathrm{O}_{20}(\mathrm{OH})_{4}$ in $1 \mathrm{~W}$ and $2 \mathrm{~W}$ layers, respectively. Other structural parameters and atomic positions in the different layer types are described in Ferrage et al. (2005).

Briefly, the fitting strategy developed by Ferrage et al. (2005) consists in using a main structure, periodic when possible, to reproduce as much as possible of the experimental XRD pattern. If necessary, additional contributions to the diffracted intensity are introduced to account for the misfit between calculated and experimental patterns. The presence of two MLSs does not imply that two populations of particles are physically present in the sample. As a result, layers with the same hydration state present in the different MLSs contributing to the diffracted intensity are assumed to have identical properties (chemical composition, layer thickness, z-coordinates of atoms). The relative proportions of the different MLSs and that of the different layer types in these MLSs were also considered as variable parameters during the fitting procedure.

Layer Charge: A detailed description of the experimental protocol and the layer charge determination can be found in Mermut and Lagaly, 2001 and Hofmann et al., 2004. All measurements were done in triplicate.

X-ray Photoelectron Spectroscopy (XPS): XPS analyses were performed using a Physical Electronics Inc. PHI 5600ci spectrometer equipped with a hemispherical capacitor analyzer and multichannel detector. Si $2 \mathrm{~s}, \mathrm{Al} 2 \mathrm{p}$ and $\mathrm{Mg} 2 \mathrm{~s}$ elemental lines were recorded by $\mathrm{Al} \mathrm{K}_{\mathrm{a}} \mathrm{X}$ ray excitation $(1486.6 \mathrm{eV})$ using a source power of $200 \mathrm{~W}$, a source - sample distance of $10 \mathrm{~mm}$ and a source - analyzer angle of $54^{\circ}$. The angle between sample surface normal and analyzer was $45^{\circ}$. Atomic concentrations were calculated from peak areas of elemental lines after Shirley background subtraction, by use of sensitivity factors and the analyzer transmission function determined at same acquisition conditions. Calibration of the $\mathrm{Si}, \mathrm{Al}$ and 
$\mathrm{Mg}$ analyses was done using synthetic $\mathrm{SiO}_{2}, \mathrm{Al}_{2} \mathrm{O}_{3}$ and $\mathrm{MgAlO}_{4}$ samples. The $\mathrm{SiO}_{2}(30 \mathrm{~nm}$ $\mathrm{SiO}_{2}$ layer on silicon wafer), $\mathrm{Al}_{2} \mathrm{O}_{3}$ (sapphire single crystal, TBC-Kelpin Co., Neuhausen) and $\mathrm{MgAlO}_{4}\left(99.985 \% \mathrm{MgAlO}_{4}\right.$ powder, Alfa Aesar) samples were purified with ethanol and afterwards sputtered with Ar ions for 10 to $80 \mathrm{sec}$. Based on the measurements of the ultrapure solids, the PHI Multipak sensitivity factors were refined for the $\mathrm{Al} \mathrm{K}_{\mathrm{a}} \mathrm{X}$-ray excitation. The detection limit of the $\mathrm{Si}, \mathrm{Al}$ and $\mathrm{Mg}$ analyses is $0.5 \mathrm{Mol} \%$.

Thermal Analysis: The measurements were performed on a STA 449 C Jupiter from NETZSCH-Gerätebau GmbH with a TG/DSC sample holder. The STA is connected with a quadruple mass spectrometer $403 \mathrm{C}$ Aëolos from IPI / InProcess Instruments / NETZSCHGerätebau GmbH. All samples were allowed to equilibrate at a relative humidity of $53 \%$ in a dessicator above saturated $\mathrm{Mg}\left(\mathrm{NO}_{3}\right)_{2}$ solution for at least $48 \mathrm{~h}$. The conditions for the STA measurement are reported in Table 1.

Infra-red spectroscopy: The IR spectra were recorded with a Perkin-Elmer 1760 spectrometer over the range $4000-400 \mathrm{~cm}^{-1}$ (optical resolution, $2 \mathrm{~cm}^{-1}$ ). The pellets were prepared by diluting $1 \mathrm{mg}$ of sample in $100 \mathrm{mg}$ of $\mathrm{KBr}$.

AFM measurements: Both a raw sample of SAz-1 and samples of SAz-1 recovered from experiments were observed by AFM. A dilute suspension of each SAz-1 Na-saturated sample was gently sonicated and centrifuged onto a crystal of highly ordered pyrolytic graphite (HOPG). The excess aqueous solution was removed and the sample dried in an oven at $40^{\circ} \mathrm{C}$. A Veeco Instruments DIMENSION 3100 AFM with Nanoscope IV controller operating in tapping mode was used for imaging the smectite particles under ambient conditions in air (after drying). High aspect ratio Si single-crystal AFM tips were used. The nominal oscillation resonance frequency of the cantilever was $283 \mathrm{kHz}$. The maximum scan rate was $5 \mathrm{~Hz}$. The 
smectite particle morphology and dimensions were quantitatively evaluated using the Image WSXM 2.0 software (NANOTEC). Using AFM, we analyzed smectite particles laying flat on the HOPG substrate. Aggregates of randomly oriented smectites were disregarded in the measurements.

Scanning electron microscopy: Scanning electron microscopy (SEM) was used to observe material of which there was too little to analyse by XRD. The SEM photographs were obtained using a JEOL GSM-6100 instrument with a KEVEX energy dispersive spectrometer used for semi-quantitative analysis (peak heights ratios).

Oxygen Isotope Analyses of clays: The oxygen isotope composition of the smectite samples was measured at the University of Tübingen, using a conventional extraction of oxygen and $\mathrm{BrF}_{5}$ reagent, according to a method adapted from Clayton and Mayeda, 1963. About $7 \mathrm{mg}$ of sample were used and the extracted oxygen was converted to $\mathrm{CO}_{2}$. The sample is wrapped in aluminium foil and dried for 3 days in an exsiccator with $\mathrm{P}_{2} \mathrm{O}_{5}$ to remove non-structural water (Savin \& Epstein, 1970). Then the samples are immediately (within seconds) loaded into the Ni-reaction vessel in a dry $\mathrm{N}_{2}$ stream and pumped for at least 2 hours at temperatures below $180^{\circ} \mathrm{C}$ before $\mathrm{BrF}_{5}$ was added. Reaction was performed at $550^{\circ} \mathrm{C}$ for $16-18 \mathrm{~h}$. Isotope measurements were made using a Finnigan MAT isotope ratio mass spectrometer (Finnigan MAT 252). Oxygen isotope compositions are given in the standard $\delta$-notation, expressed relative to VSMOW in permil (\%o). The precision of $\delta^{18} \mathrm{O}$ values was better than $0.2 \%$ when compared to the reference $\delta^{18} \mathrm{O}$ values for NBS-28 of $9.64 \%$.

The $1 \mathrm{M} \mathrm{KOH}$ fluid was analysed for total oxygen isotope composition $\left(\mathrm{H}_{2} \mathrm{O}+\mathrm{KOH}\right)$ using a TC-EA preparation device connected online with a Finnigan MAT Delta + XL continuous 
flow mass-spectrometer. $0.5 \mu \mathrm{l}$ liquid was filled in a silver container and combusted at $1450^{\circ}$ C. The analytical precision is better than $\pm 0.3 \%$.

Solution compositions: Concentrations of dissolved $\mathrm{Si}, \mathrm{Al}, \mathrm{K}, \mathrm{Fe}$ and $\mathrm{Mg}$ were determined for all samples. The Si and Al were analysed using a Plasma 400 ICP-AES (Perkin Elmer). All measurements were done in triplicate.

\section{Results}

XRD: For Sr-saturated SAz-1 specimen the position of the 001 reflection is $\sim 15.3 \AA$ (Fig. 1). With increasing reaction time, the profile of this reflection is slightly broadened and becomes asymmetrical on the high-angle side. Profile broadening may be related to a decrease of the coherent scattering domain size but the asymmetry on the high-angle side of the 001 reflection is more likely attributed to the presence of layers with lower layer thickness. The increased proportion of these layers is best revealed by XRD profile modelling. Structure models and structural parameters used to fit the 001 reflection are reported in Table 2 . In agreement with structure models determined by Ferrage et al. (2004) on the $<1 \mu \mathrm{m}$ fraction of Sr-saturated SAz-1, two MLSs were used to reproduce the 001 reflection. The first one is mainly constituted by $2 \mathrm{~W}$ layers with minor $1 \mathrm{~W}$ layers (S1) whereas the second one is more heterogeneous and incorporates the three layer types (S2).

XRD measurements at $40 \% \mathrm{RH}$ of the Sr-saturated samples reveal some changes in the expandability of the smectite. With increasing alteration time the compositions of the two MLSs remain constant except for the last two samples in which an increase of $1 \mathrm{~W}$ layers is observed in both contributions. A modification in expandability is observed, mainly induced by the increase of the $\mathrm{S} 2: \mathrm{S} 1$ ratio for reaction times up to 45 days (Table 2). As a result the 
number of $1 \mathrm{~W}$ layers increases whereas that of $0 \mathrm{~W}$ layers seems to be about constant with reaction time. The layer thickness of the different layer types were found constant whereas CSDS of the crystals decreases from 5.4 to 4.3 after 45 days and remains then constant till the end of the experiment (Table 2). Some $\mathrm{SrCl}_{2}$ and $\mathrm{SrCO}_{3}$ peaks were found as impurities resulting from the $\mathrm{Sr}^{2+}$-saturation procedure. In addition, low intensity sharp peaks, likely attributed to zeolite-type minerals (phillipsite), were observed for reacted samples.

Observation of the (060) peak region gives information on the a-b portion of the phyllosilicate structures. This region was monitored as a function of reaction time (Fig. 2). The appearance of a small peak at $1.54 \AA$ beside the initial peak at $1.49 \AA$ indicates the formation of trioctahedral coherently diffracting domains (Brindley and Brown, 1980). A similar observation was made by Beaufort et al., 2001 under neutral $\mathrm{pH}$ conditions at higher temperatures $\left(100^{\circ} \& 200^{\circ} \mathrm{C}\right)$. More importantly, there is a clear shift in the position of the (060) peak of the major phase towards higher spacings. Is indicates a change in the internal structure of the aluminous smectite. Such a shift is indicative of an increase in layer charge, either for beidellite or montmorillonite substitutions in the lattice (Velde, 1985).

Solution chemistry: The changes in solution composition with time were monitored during the reaction. Due to the high $\mathrm{KOH}$ content, no significant variation of $\mathrm{pH}$ has been observed. After a first strong increase of the $\mathrm{Al}$ and $\mathrm{Si}$ concentration in solution the concentration increase flattens out to remain constant within the error of the measurement at $\sim 950 \mathrm{mg} / \mathrm{L}$ for $\mathrm{Si}$ and $\sim 250 \mathrm{mg} / \mathrm{L}$ for $\mathrm{Al}$ (Fig. 3). With increasing reaction time the $\mathrm{Al} / \mathrm{Si}$ ratio in solution decreases from 0.39 to 0.25 . The solution concentrations of $\mathrm{Mg}$ and $\mathrm{Fe}$ were about $0.06 \mathrm{mg} / \mathrm{L}$ and $0.3 \mathrm{mg} / \mathrm{L}$, respectively, throughout the experiment. 
The $\mathrm{pH}$ and aqueous species, as well as the saturation index of possible precipitates, were calculated at in-situ conditions by using the EQ3/6 software package (Wolery et al., 1988) and the SUPCRT92 database (Johnson et al., 1992). The in-situ pH was determined by calculating the charge balance on $\mathrm{H}^{+}$. We checked that the presence of small amounts of other cations does not change the $\mathrm{pH}$ calculations, given the high potassium concentrations.

Layer Charge: We observed a continuous evolution of the layer charge with increasing reaction time. We measured a mean layer charge of $0.32 \mathrm{eq} /(\mathrm{Si}, \mathrm{Al})_{4} \mathrm{O}_{10}$ for the initial $\mathrm{SAz}-1$ which is in agreement with the value reported by Mermut and Lagaly, 2001 but lower than the value reported by Jaynes and Bigham, 1987. The mean layer charge shows an increase from $0.36 \mathrm{eq} /(\mathrm{Si}, \mathrm{Al})_{4} \mathrm{O}_{10}$ after 5 days to a value of $0.42 \mathrm{eq} /(\mathrm{Si}, \mathrm{Al})_{4} \mathrm{O}_{10}$ at the end of the experiment (Fig. 4a). The initial SAz-1 shows a heterogeneous charge distribution containing $\sim 4 \%$ of layers with a charge $>0.4 \mathrm{eq} /(\mathrm{Si}, \mathrm{Al})_{4} \mathrm{O}_{10}$ (Fig. 4b). With increasing run time the layer charge distribution is shifted towards higher charge densities. After 150 days more than $\sim 37 \%$ of the smectite layers have a charge higher than 0.4 eq/(Si,Al $)_{4} \mathrm{O}_{10}$ (Fig. $\left.4 \mathrm{~b}\right)$.

XPS/SEM: The $\mathrm{Al} / \mathrm{Si}$ and the $\mathrm{Mg} / \mathrm{Si}$ atomic ratios of the Na-saturated solids were measured to follow changes in smectite chemistry as a function of reaction progress. Both ratios increase as a function of reaction time indicating the increase of $\mathrm{Al}$ and $\mathrm{Mg}$ in the smectite structure. The rise of the $\mathrm{Al} / \mathrm{Si}$ atomic ratio as function of a reaction time from 0.39 to 0.48 after 150 days was observed (Fig. 5). The $\mathrm{Mg} / \mathrm{Si}$ ratio increased from 0.17 to 0.3 after 150 days (Fig. 5). The initial values of 0.39 and 0.17 measured on the initial smectite are in perfect agreement with the values measured by Metz et al., 2005 for SAz-1 montmorillonite. SEM observations were carried out to verify the formation of precipitated aluminium or magnesium bearing phases which are below the detection limit of XRD. Some rare small brucite crystals but no Al-bearing phases were found after 80 days of reaction time with SEM. Although the 
information depth of the XPS signal is $6.3 \mathrm{~nm}$, it cannot be concluded a priori that using the XPS only a surface layer of around five smectite layers is analyzed. Homogenously distributed contaminants may be detected by the XPS signal as well, because the analyzed sample area is about $1 \mathrm{~mm}^{2}$. However, accessory minerals which are within a smectite aggregate or covered by a smectite coating would not be included in the XPS analysis. Some $\mathrm{SrCl}_{2}$ impurities were found by SEM and during XPS analysis.

STA measurements: For the STA measurements we used sodium saturated samples. Based on the dehydroxylation temperature of $643^{\circ} \mathrm{C}$ the SAz-1 is a cis-vacant (cv) smectite (Drits et al., 1995; Emmerich and Kahr, 2001). With increasing reaction time the dehydroxylation temperature decreases continuously to $605^{\circ} \mathrm{C}$ after 150 days (Fig. 6). In addition a second (small) dehydroxylation peak occurred at about $790^{\circ} \mathrm{C}$ after 80 days of reaction time which may be attributed to a trioctahedral smectite.

The dehydration temperature of the initial sodium saturated smectite was measured to be $147^{\circ} \mathrm{C}$. For the first 80 days the dehydration temperature varies within the error of the measurement. After 150 days the dehydration reaction splits and a second maximum at $127^{\circ} \mathrm{C}$ was observed in DSC curves (Fig. 6). TG measurements demonstrate that the amount of interlayer water increased from about $12 \%$ of the untreated Na-saturated SAz-1 to about 17 $\%$ after 150 days of reaction.

Infra-Red: IR spectroscopy revealed unchanged smectite spectra for all the experiments. No loss of intensity of vibration bands as a function of reaction time was observed. A weak band at $792 \mathrm{~cm}^{-1}$ indicating traces of poorly crystalline silica disappeared with increasing reaction time (Madejova and Komadel, 2001). No band at $\sim 3680 \mathrm{~cm}^{-1}$ was detected in the reaction products which would indicate the presence of a trioctahedral smectite. 
AFM: An AFM image of Na-saturated smectite particles after 150 days reaction time is shown in Fig. 7. The AFM analysis of the initial and the reacted particles indicate no major morphological changes throughout the experiment. Therefore, the following description includes all samples. The particles consist of irregular and fine grained plates. Mostly the edges are rounded, but straight edges appear as well. The top view shape of the particles resembles an ellipse. The height and the surface area of each of the selected particles were measured. In all 400 heights and 350 surface area measurements were performed. The distribution of the heights measurements for the initial smectite and the Reactor 6: 150 days sample show no change in particle morphology, particle height and surface area. The number of layers in the smectite particles was calculated assuming that the thickness of a single TOT layer with the hydrated sodium layer was about $12.5 \AA$ (Jasmund and Lagaly, 1993). Since diluted smectite suspensions were used and the samples were dispersed during the preparation for the AFM measurements the majority of the particles consists of 1-5 TOT layers (Fig. 7).

Oxygen Isotope Analyses: The oxygen-isotope composition of the Na-saturated clays was monitored to provide another measure of reaction progress and is shown for the initial and the reacted smectites in Fig. 8. The $\delta^{18} \mathrm{O}$ values of the clays changed rapidly from $\delta^{18} \mathrm{O}=17.4 \%$ for the initial SAz-1 to a value of $\delta^{18} \mathrm{O}=15.2 \%$ for the reacted smectite after 150 days. A similar trend was observed by Whitney and Northrop, 1988 at higher temperatures $\left(250^{\circ}\right.$ $450^{\circ} \mathrm{C}$ ) for the SWy-1 smectite in distilled water. The composition of the water in the experiment was $-7.5 \%$. The isotope values change with time, decreasing rapidly in the beginning before attaining a value near $15.2 \%$, which shows only partial exchange with the aqueous solution oxygen. The initial exchange is most likely one of surface interaction. If dissolution - recrystallization occurred one would expect greater exchange between solution and silicate material. 


\section{Discussion}

The major objective of the present study is to demonstrate changes in mineral structure of a smectite at low temperatures under conditions of high alkalinity. Other studies have been performed on similar material but not a low temperature. Several different methods were used to obtain information on mineral evolution during the experiments.

\section{Direct observation of crystal morphology}

AFM observations of crystallite size, shape and thickness supports the hypothesis that the process is dominated by SST (Baronnet, 1997). The materials appear to retain their outer morphology but change their internal crystallographic composition.

\section{Measurements of structural change}

\section{XRD}

In contrast to Whitney and Northrop, 1988 and Bauer and Velde, 1999 the initial and reacted smectites were measured in the Sr-saturated state at a fixed relative humidity. Under these conditions misinterpretation of dehydrated layers for illite layers can be neglected. XRD and infrared spectra gave little evidence for a change in smectite mineralogy in our experiments. The number of expandable layers with one water layer increases, whereas the portion of the 0 water layers is about constant with reaction time. This suggests an increase in overall layer charge on the smectite. The peak width of the (001) reflections increases with reaction time suggesting a decrease in average diffracting domain. The peak position of the (060) band increases suggesting a change in internal mineral composition and an increase in charge on the structures. The layer charge using XRD and alkyl-ammonium treatments was found to increase from 0.32 to 0.42 and a clear shift in the layer charge distribution towards high charge layers was observed. Small amounts of a trioctahedral mineral were apparent (from (060) peak measurements) which indicates an increase of magnesium in the smectite. 


\section{MS measurements}

The dehydroxylation temperature decreased from $643^{\circ}$ to $605^{\circ} \mathrm{C}$. This shift confirms the increased layer charge of the smectite. A lower dehydroxylation temperature for smectites with higher layer charge has been observed by Schultz (1969) and Michot et al. (2005). In smectites, the octahedral sheet tends to be cis-vacant while the illites have mainly trans-vacant disposition (Drits et al., 1998). It is evident that the reacted smectite has a different disposition of the hydroxyl groups but that the cis-vacant character of the octahedral sheet remained nearly unchanged throughout the experiment. A second but small dehydroxylation appeared at $790^{\circ} \mathrm{C}$. A similar observation was made by Emmerich and Kahr (2001) for a de- and rehydroxylated Na-saturated cv smectite. XRD measurements of the 060 reflex indicate the appearance of trioctahedral Mg-smectite layers which is consistent with the XPS data showing an increase of Mg in the smectite structure (Fig. 5) and XRD data for the (060) peak indicating a small amount of a trioctahedral phase.

MS curves for the Na-saturated samples SAz-1 and the resaturated Reactor 6: 150 days sample are shown in Fig. 6. The amount of adsorbed water depends on the nature of the interlayer cations, the pre-treatment of the sample and the silica lattice (Grim, 1968). Two types of the water molecules can be distinguished in the interlayer space of smectites: filling water which belongs to outer hydration shells of the cations or is bound to the surface of the smectite layers; and water belonging to the first hydration shell of the exchangeable cations.

Both smectites in Fig. 6 have the same interlayer cation and the same pre-treatment so that the differences can be attributed to changes in the silica lattice and as a consequence in the number of interlayer cations. It is evident that with increasing layer charge more cations are needed to compensate the charge deficit. This was confirmed by TG measurements which indicate an increase of the interlayer water from 12 to $17 \%$ after 150 days of reaction time 
corresponding to increase of about 8 to 10 water molecules per cation $\mathrm{Na}^{+}$. These numbers are within the range of the values for Na-saturated saponites dominated by $2 \mathrm{~W}$ layers Michot et al. (2005). This is an important observation because it means that the hydration sphere of the $\mathrm{Na}^{+}$cations is already sufficient to induce the major presence of $2 \mathrm{~W}$ layers from the beginning. This means that additional $\mathrm{H}_{2} \mathrm{O}$ molecules are not strongly bound to interlayer cations. In turn they should be easier to remove. In our experiments the occurrence of a second dehydration reaction centred at $127^{\circ} \mathrm{C}$ after 150 days was observed (Fig. 6). This is in contradiction to what someone would expect when the amount of absorbed water increases but it is consistent with the water vapor adsorption-desorption isotherms reported by Michot et al., 2005 that show a transition towards higher hydration states at lower $\mathrm{P} / \mathrm{P}_{0}$ values. As we know meanwhile hydrated smectites consist of $\% 2 \mathrm{~W}, \% 1 \mathrm{~W}, \% 0 \mathrm{~W}$ layers that superimpose in one peak which is often not resolved in DSC or MS curves. In addition water adsorbed on clay surfaces contributes to observed dehydration.

\section{Measurements of chemical change}

Oxygen constitutes the structural skeleton of the reacting materials, the degree of isotopic resetting can be used to indicate the extent of rearrangement of the mineral structure at high temperatures (Whitney and Northrop, 1988). The initial rapid shift in $\delta^{18} \mathrm{O}$ values of $2.2 \%$ to more negative values for the reacted smectites is in agreement with an exchange of structural surface oxygen with water/KOH oxygen. This is due to the negative $\delta^{18} \mathrm{O}$ value of the exchange fluid (-7.4\%o). According to Kohn and Valley, 1998 and Sheppard and Gilg, 1996 for temperatures of $80^{\circ} \mathrm{C}$ a fractionation of around $+19 \%$ o for smectite - fluid exchange applies, which would yield an end value of $+12 \%$ for a smectite in equilibrium with the fluid. Since at a solid/liquid ratio of $1 / 80$ the $\delta^{18} \mathrm{O}$ value of the liquid can be regarded as constant throughout experiment run time. A rapid initial shift of the oxygen isotope ratio followed by a decrease in reaction rate with time in the reacted smectites can be observed. The isotope data 
can be taken to indicate a rapid equilibration of the solids with the aqueous solution. This would indicate no significant recrystallization of the smectite material.

XPS data showed that the increase of aluminium in the structure (increase of the $\mathrm{Al} / \mathrm{Si}$ ratio from 0.39 to 0.48 ) is responsible for the increase in the layer charge. This is consistent with the solution chemistry which indicates an increase in silica in solution and magnesium relative to aluminium.

Chemical measurements of dissolved species and oxygen isotopes of solids indicates that little dissolution occurred but significant change in the overall composition of the solids is seen through changes in solution composition.

\section{Comparison with previous experiments}

Our results are consistent with previous studies which were conducted at neutral $\mathrm{pH}$ and higher temperatures $\left(100^{\circ}\right.$ and $\left.250^{\circ} \mathrm{C}\right)$ with various sources of potassium. Howard and Roy 1985 found the formation of high-charged layers when montmorillonite reacted at $150^{\circ}$ and $250^{\circ} \mathrm{C}$. Eberl et al., 1978 and Whitney, 1992 found that the formation of high-charge layers is promoted by an increase of potassium in the system. Yamada and Nakasawa, 1993 observed the formation of a beidellite plus saponite assemblage after the experimental alteration of synthetic beidellite-montmorillonite mixed-layers at high temperatures. Beaufort et al., 2001 observed during montmorillonite alteration at $100^{\circ}$ and $200^{\circ} \mathrm{C}$ the formation of trioctahedral Mg-smectite and high-charge beidellitic layers. The beidellite + saponite assemblage is also observed between $100^{\circ}-200^{\circ} \mathrm{C}$ in active geothermal fields where montmorillonite seems to be no longer stable at temperatures $>100^{\circ} \mathrm{C}$ (Beaufort et al., 1995). 


\section{Process of mineral change}

Given the observations of crystal structure (diffracting domain size, a-b cell size dimensions, direct AFM observations of crystal dimensions) it appears that there is a change with reaction time in the smectite structure. This seems to be due to the substitution of $\mathrm{Al}$ and $\mathrm{Mg}$ for $\mathrm{Si}$ in the smectite which creates smaller coherent diffraction domains in the structure without necessitating a dissolution - re-crystallization of the silicate mineral.

The observations cited above indicate that there is a significant, gradual change in the mineral cation composition of the 2:1 layers of smectite in the presence of $\mathrm{KOH}$ solution. The smectite minerals become higher charged, and have smaller coherent diffracting domains. This involves significant chemical changes within the mineral crystallites. Aluminium and magnesium substitutes for silicon to a significant degree. The question is then: How does this happen? Essentially two pathways can be proposed according to classical theories: dissolution/crystallization or solid state transition.

If dissolution/precipitation is not the mechanism of mineral chemical change, one must accept a mechanism of diffusive modification within the existing crystallites. This change occurs at low temperatures, $80^{\circ} \mathrm{C}$. Such a conclusion is surprising given the assumed very low rate of ionic diffusion in silicate crystallites at low temperatures (Kyser and Kerrich, 1991). However, the experimental evidence shown here strongly rejects the hypothesis of dissolution and crystallization, the other alternative to mineral change in aqueous solutions.

The conclusion of diffusion mechanism of mineral change at low temperatures is surprising. Yet if one considers the great complexity and range of solid solution common in low temperature clay minerals, one can suspect that important mineral compositional change occurs at these low temperatures. Normally one attributes high solid solutions in solids to high 
thermal energy but it is known that chemical variability can also increase at lower temperatures in systems such those where illite is stable (Velde, 1985).

We propose that the phenomenon of chemical change at low temperatures is one of a response to new chemical conditions inducing a larger range in chemical composition which, in the case studied, increases the alumina and magnesium content of the smectite minerals observed. In this particular instance the change is accomplished by internal diffusion within the smectite crystallites.

Acknowledgement: We thank Klaus Spieler and Eva Soballa (INE) for their technical assistance during the SEM measurements and Dieter Schild (INE) for performing the XPS analysis. We would like to thank Heike Pieper and Dirk Bosbach for their help performing the AFM measurements. 
Literature

Altaner, S.P., and Ylagan, R.F. (1997) Comparison of structural models of mixed-layer illite/smectite and reaction mechanisms of smectite illitization. Clays and Clay Minerals, 45(4), 517-533.

Awwiller, D.N. (1993) Illite/smectite formation and potassium mass transfer during burial diagenesis of mudrocks: a study from the Texas Gulf Coast Paleocene-Eocene. Journal of Sedimentary Petrology, 63, 501-512.

Baronnet, A. (1997) Silicate microstructures at the sub-atomic scale. Comptes Rendus De L Academie Des Sciences Serie Ii Fascicule a-Sciences De La Terre Et Des Planetes, 324(3), 157-172.

Bauer, A., and Velde, B. (1999) Smectite transformation in high molar KOH solutions. Clay Minerals, 34(2), 259-273.

Beaufort, D., Berger, G., Lacharpagne, J.C., and Meunier, A. (2001) An experimental alteration of montmorillonite to a di plus trioctahedral smectite assemblage at 100 and 200 degrees C. Clay Minerals, 36(2), 211-225.

Beaufort, D., Papapanagioto, P., Patrier, P., and Traineau, H. (1995) Les interstratifies I-S et C-S dans les champs geothermiques actifs: sont-ils comparables ceux des series diagenetiques? Bulls. Centr. Rech. Elf Aquitaine Prod., 19, 267-294.

Brindley, G.W., and Brown, G. (1980) Crystal Structures of Clay Minerals and their X-ray Identification. 125-195 p. Mineralogical Society, London.

Clayton, R.N., and Mayeda, T.K. (1963) The use of bromine pentafluoride in the extraction of oxygen from oxides and silicates for isotopic analysis. Geochim. Cosmochim. Acta, 27, 43-52.

Cuadros, J., and Altaner, S.P. (1998) Characterization of mixed-layer illite-smectite from bentonites using microscopic, chemical, and X-ray methods: Constraints on the smectiteto-illite transformation mechanism. American Mineralogist, 83(7-8), 762-774.

Day, P.R. (1965) Particle Fractionation and particle size analysis. In B.C. A., Ed. Methods of Soil Analysis, p. 545-567.

Drits, V.A. (1985) Mixed-layer minerals: Diffraction methods and structural features. In L.G. Schultz, H. Van Olphen, and F.A. Mumpton, Eds. International Clay Conference, p. 3345. Clay Minerals Society, Denver.

Drits, V.A., Besson, G., and Muller, F. (1995) An improved model for structural transformations of heat- treated aluminous dioctahedral 2:1 layer silicates. Clays and Clay Minerals, 43(6), 718-731.

Drits, V.A., Lindgreen, H., Sakharov, B.A., and Salyn, A.S. (1997a) Sequence structure transformation of illite-smectite-vermiculite during diagenesis of Upper Jurassic shales, North Sea. Clay Minerals, 33.

Drits, V.A., Lindgreen, H., Salyn, A.L., Ylagan, R., and McCarty, D.K. (1998) Semiquantitative determination of trans-vacant and cis-vacant $2: 1$ layers in illites and illite-smectites by thermal analysis and X-ray diffraction. American Mineralogist, 83(1112), 1188-1198.

Drits, V.A., and Sakharov, B.A. (1976) X-Ray structure analysis of mixed-layer minerals. 256 p. Dokl. Akad. Nauk SSSR, Moscow.

Dunoyer de Segonzac, G. (1970) The transformation of clay minerals during diagenesis and low-grade metamorphism: A review. Sedimentology, 15, 281-346.

Eberl, D.D., Srodon, J., and Northrop, H.R. (1986) Potassium Fixation in Smectite by Wetting and Drying. Acs Symposium Series, 323, 296-326.

Eberl, D.D., Velde, B., and Mc Cormick, T. (1993) Synthesis of illite-smectite from smectite at Earth surface temperatures and high pH. Clay Minerals, 28, 49-60. 
Eberl, D.D., Whitney, G., and Khoury, H. (1978) Hydrothermal reactivity of smectite. American Mineralogist, 63, 401-409.

Emmerich, K., and Kahr, G. (2001) The cis- and trans-vacant variety of a montmorillonite: an attempt to create a model smectite. Applied Clay Science, 20(3), 119-127.

Ferrage, E. (2004) Etude expérimentale de l'hydratation des smectites par simulation des raies 00L de diffraction des rayons X. Implications pour l'étude d'une perturbation thermique sur la minéralogie de l'argilite du site Meuse-Haute Marne., p. 321. Université Joseph Fourier, Grenoble,

Ferrage, E., Lanson, B., Sakharov, B.A. and Drits, V.A. (2005a) Investigation of smectite hydration properties by modeling of X-ray diffraction profiles. Part 1. Montmorillonite hydration properties. Amer. Mineral. (in press).

Grim, R.E. (1968) Clay Mineralogy. McGraw-Hill Book Company, New York.

Hofmann, H., Bauer, A., and Warr, L.N. (2004) Behaviour of smectite in strong salt brines under conditions relevant to the disposal of low- to medium-grade nuclear waste. Clays and Clay Minerals, 52(1), 14-24.

Howard, J.J., and Roy , D.M. (1985) Development of layer charge and kinetics of experimental smectite alteration. Clays and Clay Minerals, 33, 81-88.

Hower, J., Eslinger, E.V., Hower, M.E., and Perry, E.A. (1976) Mechanism of burial metamorphism of argillaceous sediment: 1. Mineralogical and chemical evidence. Geological Society of America Bulletin, 87, 725-737.

Jasmund, K., and Lagaly, G. (1993) Tonminerale und Tone. Struktur, Eigenschaften, Anwendung und Einsatz in Industrie und Umwelt. 490 p. Steinkopff Verlag.

Jaynes, W.F., and Bigham, J.M. (1987) Charge reduction, octahedral charge, and lithium retention in heated, Li-satured smectites. Clays and Clays Minerals, 35(6), 440-448.

Johnson, J.W., Oelkers, E.H., and Helgeson, H.C. (1992) Supcrt92 - a Software Package for Calculating the Standard Molal Thermodynamic Properties of Minerals, Gases, Aqueous Species, and Reactions from 1-Bar to 5000-Bar and 0-Degrees-C to 1000-Degrees-C. Computers \& Geosciences, 18(7), 899-947.

Kohn, M.J., and Valley, J.W. (1998) Oxygen isotope geochemistry of the amphiboles: Isotope effects of cation substitutions in minerals. Geochimica et Cosmochimica Acta, 62(11), 1947-1958.

Kyser, T.K., and Kerrich, R. (1991) Retrograde exchange of hydrogen isotopes between hydrous minerals and water at low temperatures. In H.P.J. Taylor, J.R. O'Neil, and I.R. Kaplan, Eds. Stable Isotope Geochemistry: A tribute to Samuel Epstein, Spec. Publ. 3, p. 409 - 422. Geochem. Soc., Washington, D.C.

Madejova, J., and Komadel, P. (2001) Baseline studies of The Clay Minerals Society Source Clays: Infrared methods. Clays and Clay Minerals, 49(5), 410-432.

Mermut, A.R., and Lagaly, G. (2001) Baseline studies of The Clay Minerals Society Source Clays: Layer-charge determination and characteristics of those minerals containing $2: 1$ layers. Clays and Clay Minerals, 49(5), 393-397.

Metz, V., Amram, A., and Ganor, J. (2005) Stoichiometry of smectite dissolution. Geochimica Cosmochimica Acta.

Meunier, A., Lanson, B., and Beaufort, D. (2000) Vermiculitization of smectite interfaces and illite layer growth as a possible dual model for illite-smectite illitization in diagenetic environments: a synthesis. Clay Minerals, 35(3), 573-586.

Michot, L.J., Bihannic, I., Pelletier, M., Rinnert, E., and Robert, J.L. (2005) Hydration and swelling of synthetic Na-saponites: Influence of layer charge. American Mineralogist, 90(1), 166-172.

Moore, D.M., and Reynolds, R.C. (1997) X-Ray Diffraction and the Identification and Analysis of Clay Minerals. Oxford University Press., New York. 
Nadeau, P.H., and Bain, D.C. (1986) Composition of Some Smectites and Diagenetic Illitic Clays and Implications for Their Origin. Clays and Clay Minerals, 34(4), 455-464.

Robertson, H.E., and Lahann, R.W. (1981) Smectite to illite conversion rates: Effects of solution chemisrty. Clays \& Clay Minerals, 29, 129-135.

Sakharov, B.A., and Drits, V.A. (1973) Mixed-layer kaolinite-montmorillonite: A comparison of observed and calculated diffraction patterns. Clays \& Clay Minerals, 21, 15-17.

Sakharov, B.A., Lindgreen, H., and Drits, V.A. (1999a) Mixed-layer kaolinite-illitevermiculite in North Sea shales. Clay Minerals, 34(2), 333-344.

Sakharov, B.A., Lindgreen, H., Salyn, A., and Drits, V. (1999b) Determination of illitesmectite structures using multispecimen XRD profile fitting. Clays and Clays Minerals, 47(5), 555-566.

Sheppard, S.M.F., and Gilg, H.A. (1996) Stable isotope geochemistry of clay minerals. Clay Minerals, 31, 1-24.

Shutov, V.D., Drits, V.A., and Sakharov, B.A. (1969) On the mechanism of a postsedimentary transformation of montmorillonite into hydromica. In L. Heller, Ed. International Clay Conference, p. 523-531. Israel University Press, Jerusalem, Tokyo, Japan.

Srodon, J., Elsass, F., McHardy, W.J., and Morgan, D.J. (1992) Chemistry of illite-smectite inferred from TEM measurements of fundamental particles. Clay Minerals, 27, 137-158.

Srodon, J., Morgan, D.J., Eslinger, E.V., Eberl, D.D., and Karlinger, M.R. (1986) Chemistry of Illite Smectite and End-Member Illite. Clays and Clay Minerals, 34(4), 368-378.

Velde, B. (1985) Clays Minerals: A physico-chemical explanation of their occurence. 427 p. Elsevier, Amsterdam.

Whitney, G. (1992) Dioctahedral smectite reactions at elevated temperatures: Effects of Kavailability, $\mathrm{Na} / \mathrm{K}$ ratio and ionic strength. Applied Clay Science, 7, 97-112.

Whitney, G., and Northrop, H.R. (1988) Experimental investigation of the smectite to illite reaction: Dual reaction mechanisms and oxygen-isotope systematics. American Mineralogist, 73, 77-90.

Wolery, T.J., Jackson, K.J., Bourcier, W.L., Bruton, C.J., Viani, B.E., and Delany, J.M. (1988) The Eq3/6 Software Package for Geochemical Modeling - Current Status. Abstracts of Papers of the American Chemical Society, 196, 23-GEOC.

Yamada, H., and Nakasawa, H. (1993) Isothermal treatments of regularly interstratified montmorillomite-beidellite at hydrothermal conditions. Clays \& Clay Miner., 41, 726730 . 


\section{Tables}

\begin{tabular}{ll}
\hline & $\mathrm{DSC} / \mathrm{TG} / \mathrm{MS}$ \\
\hline Sample amount & $50 \mathrm{mg}$ \\
Grain size & powder \\
Packing density & loosely packed, no pressing \\
Reference material & Empty crucible with lid \\
Furnace atmosphere & $50 \mathrm{ml} / \mathrm{min}$ air $+20 / \mathrm{ml} / \mathrm{min}$ \\
& $\mathrm{N}_{2}$ \\
Crucibles & $\mathrm{Pt}$ with lid \\
Thermocouples & $\mathrm{Pt} / \mathrm{Pt}_{90} \mathrm{Rh}_{10}$ \\
Heating rate & $10 \mathrm{~K} / \mathrm{min}$ \\
Temperature range & $35-1000{ }^{\circ} \mathrm{C}$ \\
\hline
\end{tabular}

Table 1: Conditions of the STA measurement

\begin{tabular}{lccccccccccc}
\hline \multicolumn{1}{c}{ Sample } & S cont. & $2 \mathrm{~W}$ & $1 \mathrm{~W}$ & 0W & LT 2W & LT 1W & LT 0W & N & $\begin{array}{l}\text { Tot. } \\
\text { 2W }\end{array}$ & $\begin{array}{c}\text { Tot. } \\
1 \mathrm{~W}\end{array}$ & $\begin{array}{c}\text { Tot. } \\
\text { 0W }\end{array}$ \\
\hline Initial & $\mathrm{S} 1: 62$ & 92 & 8 & 0 & 15.30 & 12.32 & 10.00 & 5.5 & 75 & 18 & 7 \\
& $\mathrm{~S} 2: 38$ & 47 & 35 & 18 & & & & & & & \\
Reactor 1 & $\mathrm{S} 1: 66$ & 92 & 8 & 0 & & & & & & \\
5 days & $\mathrm{S} 2: 34$ & 47 & 35 & 18 & 15.30 & 12.32 & 10.00 & 5.4 & 77 & 17 & 6 \\
Reactor 2 & $\mathrm{S} 1: 64$ & 92 & 8 & 0 & & & & & & & \\
10 days & $\mathrm{S} 2: 36$ & 47 & 35 & 18 & 15.30 & 12.32 & 10.00 & 4.9 & 76 & 18 & 6 \\
Reactor 3 & $\mathrm{S} 1: 58$ & 92 & 8 & 0 & & & & & & & \\
15 days & $\mathrm{S} 2: 42$ & 47 & 35 & 18 & 15.30 & 12.32 & 10.00 & 4.6 & 73 & 19 & 8 \\
Reactor 4 & $\mathrm{S} 1: 58$ & 92 & 8 & 0 & & & & & & & \\
44 days & $\mathrm{S} 2: 42$ & 47 & 35 & 18 & 15.30 & 12.32 & 10.00 & 4.3 & 73 & 19 & 8 \\
Reactor 5 & $\mathrm{S} 1: 57$ & 85 & 15 & 0 & & & & & & & \\
80 days & $\mathrm{S} 2: 43$ & 47 & 35 & 18 & 15.30 & 12.32 & 10.00 & 4.3 & 69 & 23 & 8 \\
Reactor 6 & $\mathrm{S} 1: 51$ & 85 & 15 & 0 & & & & & & & \\
150 days & $\mathrm{S} 2: 49$ & 40 & 40 & 20 & 15.30 & 12.32 & 10.00 & 4.3 & 63 & 27 & 10 \\
\hline
\end{tabular}

The relative contribution (S cont.) of the two structures S1 and S2 is given in \% as well as the proportion of bi-hydrated, mono-hydrated and dehydrated layers $(2 \mathrm{~W}, 1 \mathrm{~W}$ and $0 \mathrm{~W}$ layers, respectively) within these elementary contributions. The total proportion of $2 \mathrm{~W}, 1 \mathrm{~W}$ and $0 \mathrm{~W}$ layers in crystal is given in $\%$ as Tot. $2 \mathrm{~W}$, Tot. $1 \mathrm{~W}$ and Tot. $0 \mathrm{~W}$, respectively. Layer thickness (LT) of the different layer type is given in $\AA$. $\mathrm{N}$ is the mean number of layers in the coherent scattering domain. The structure model of initial sample is given from the study of Ferrage, 2004

Table 2. Optimum structural parameters used for the simulation of XRD profiles. 
Figures

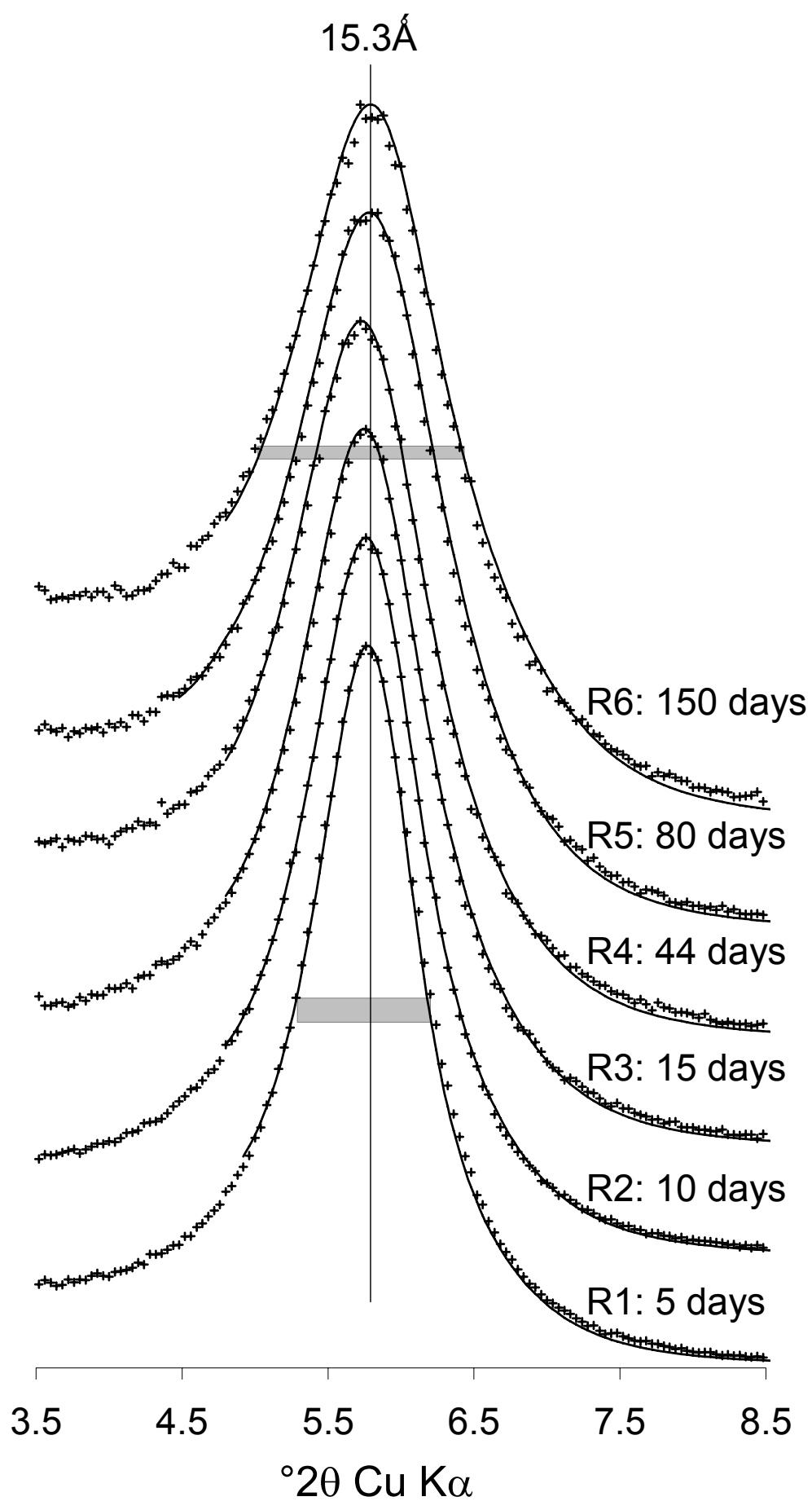

Figure 1 Comparison between experimental (crosses) and calculated (solid line) XRD patterns for the reacted $\mathrm{Sr}^{2+}$ saturated $\mathrm{SAz}-1$ recorded at $40 \%$ relative humidity. The grey bars outline the modifications in peak width between 5 days and 150 days of reaction time. 


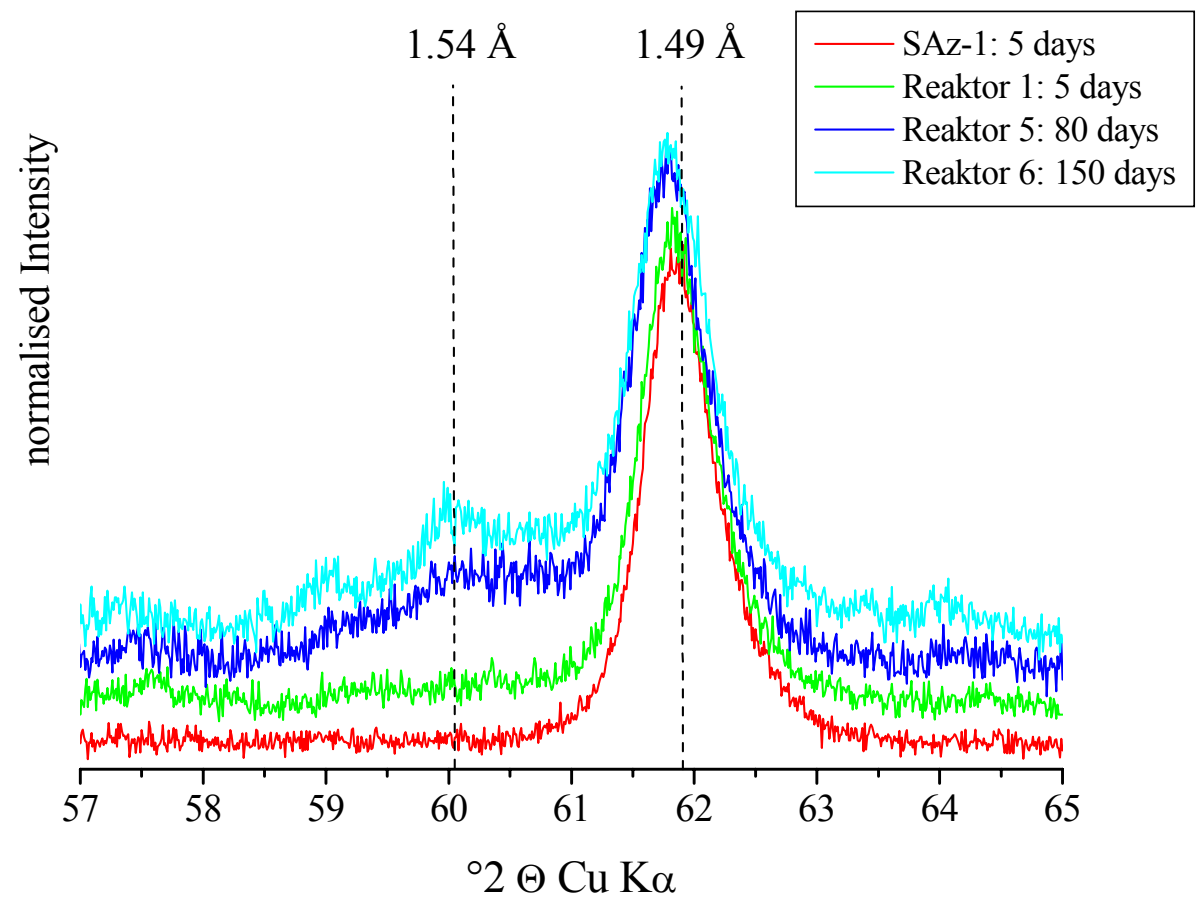

Figure 2 Evolution of the 060 bands as a function of reaction time.

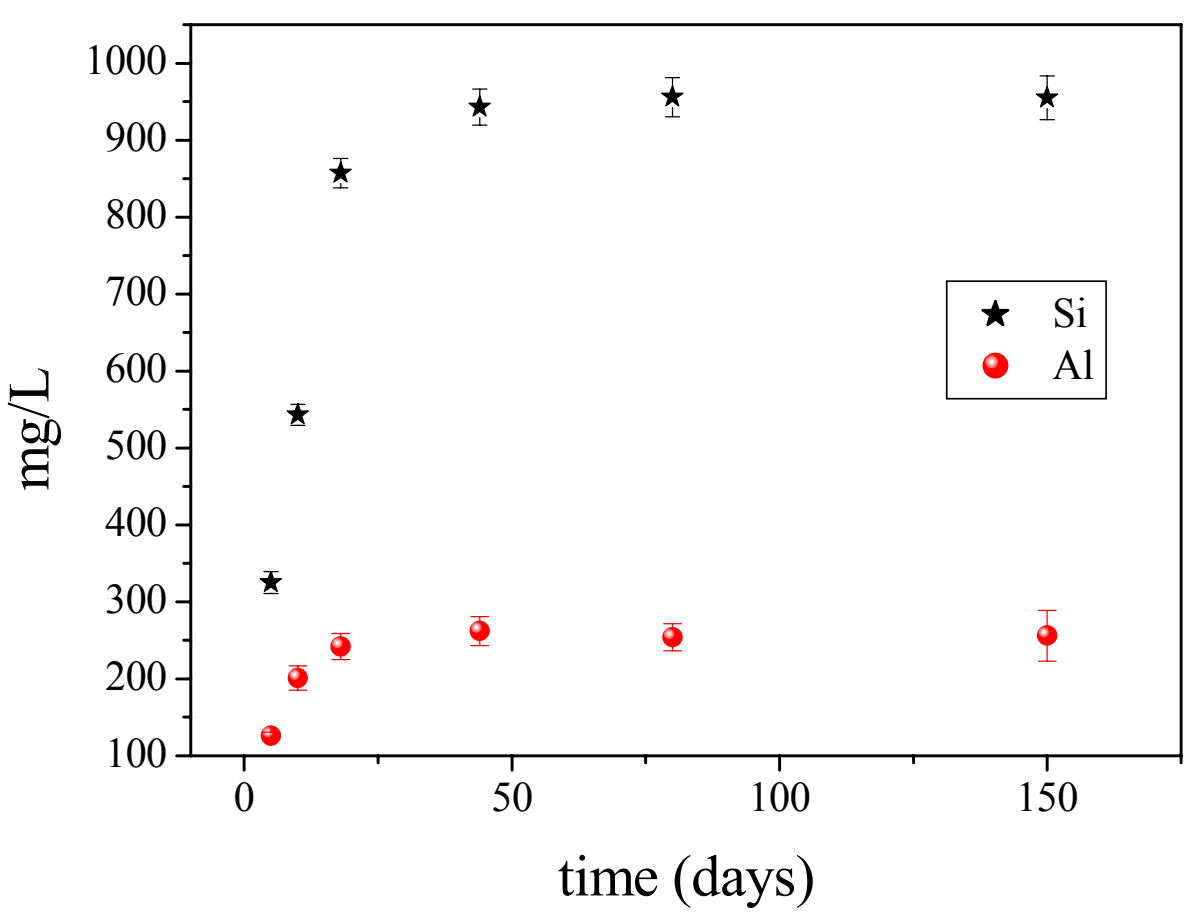

Figure 3 Plot of the released $\mathrm{Si}$ and $\mathrm{Al}$ concentrations as a function of the $\mathrm{pH}$ for $25^{\circ}$, $60^{\circ}$ and $80^{\circ} \mathrm{C}$. Error bars correspond to the standard deviation of triplicates. 


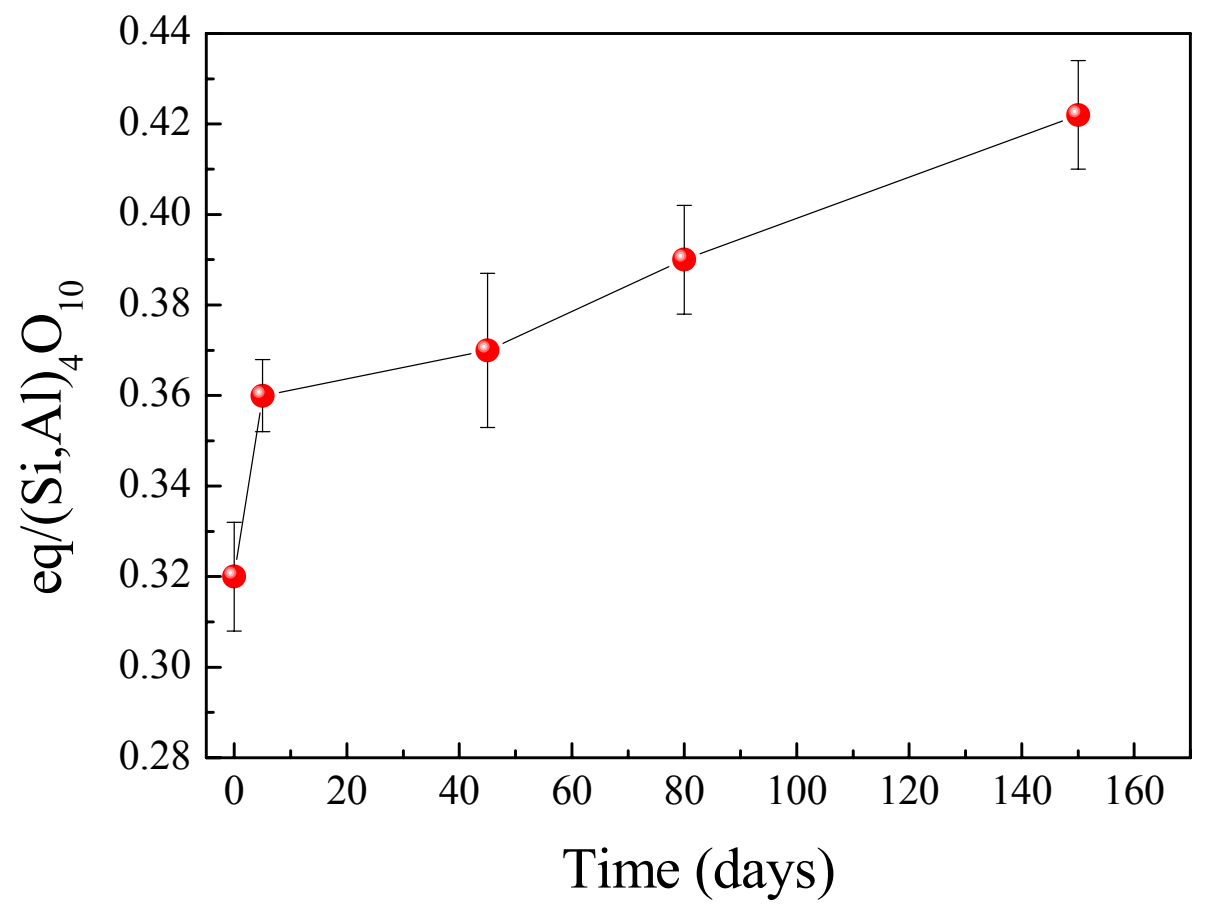

Figure 4a Evolution of the layer charge as a function of reaction time. Error bars correspond to the standard deviation of triplicates.

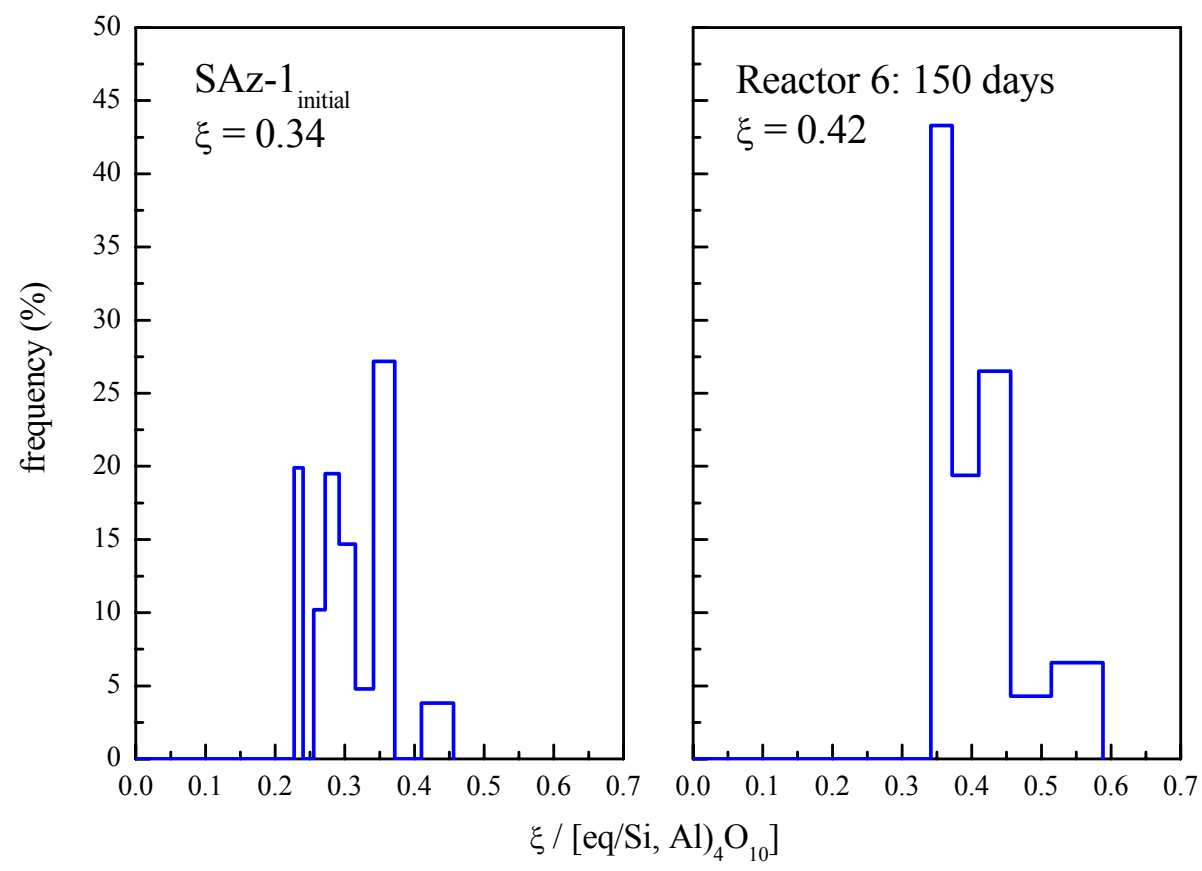

Figure $4 \mathrm{~b}$ Plot of the evolution of the layer charge distribution of the initial SAz-1 smectite and after 150 days reaction time. 


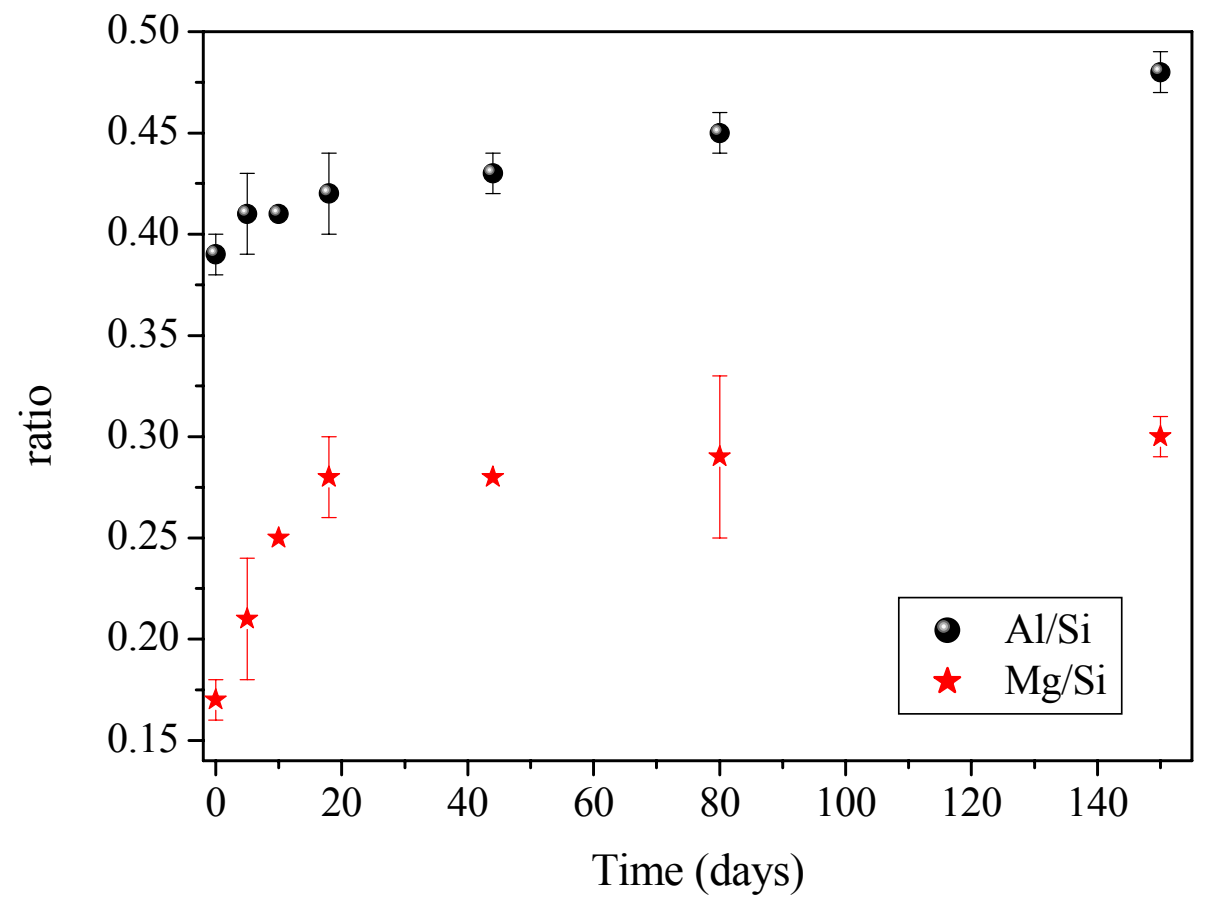

Figure 5 Plot of the Al/Si ratio of the clay from XPS as a function of reaction time. Error bars correspond to the standard deviation of triplicates.

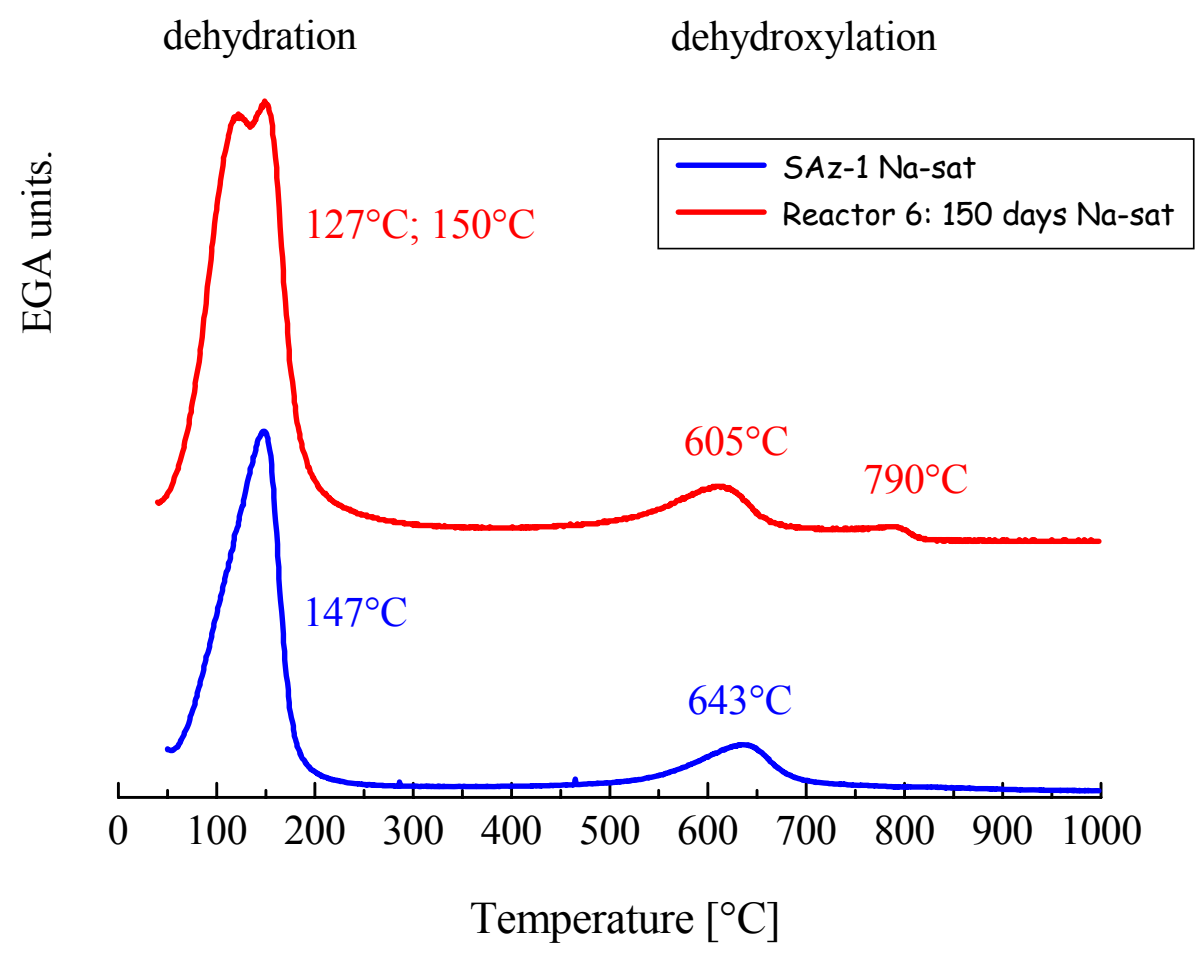

Figure 6 MS curves of the evolved water $(\mathrm{m} / \mathrm{e}=18)$ during STA measurement 

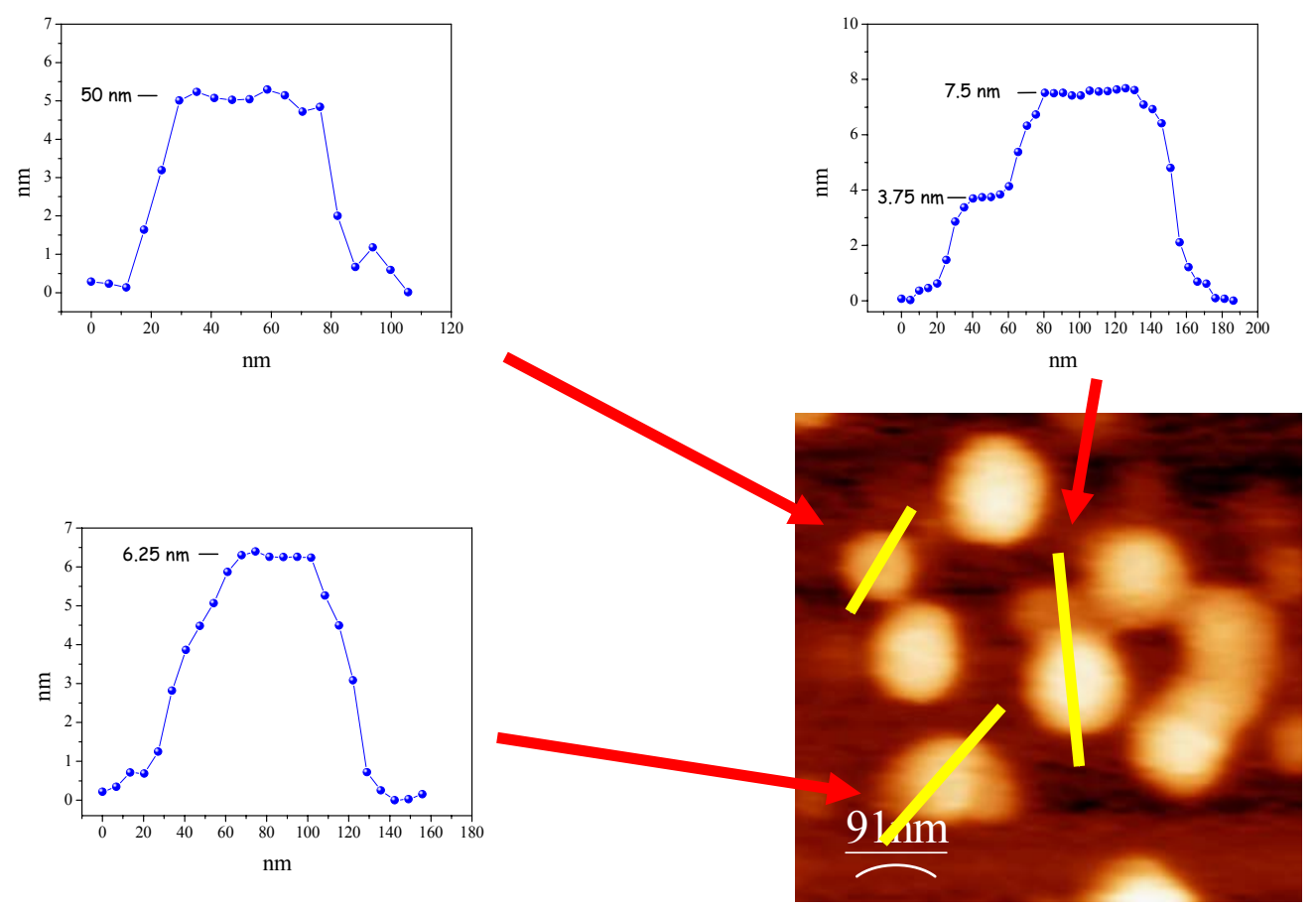

Figure 7 An AFM image of Na-saturated smectite particles in Reactor 6: 150 days. The particles consist of irregular and fine grained plates with rounded edges. The three graphs show that the particles consists of 1-5 TOT layers.

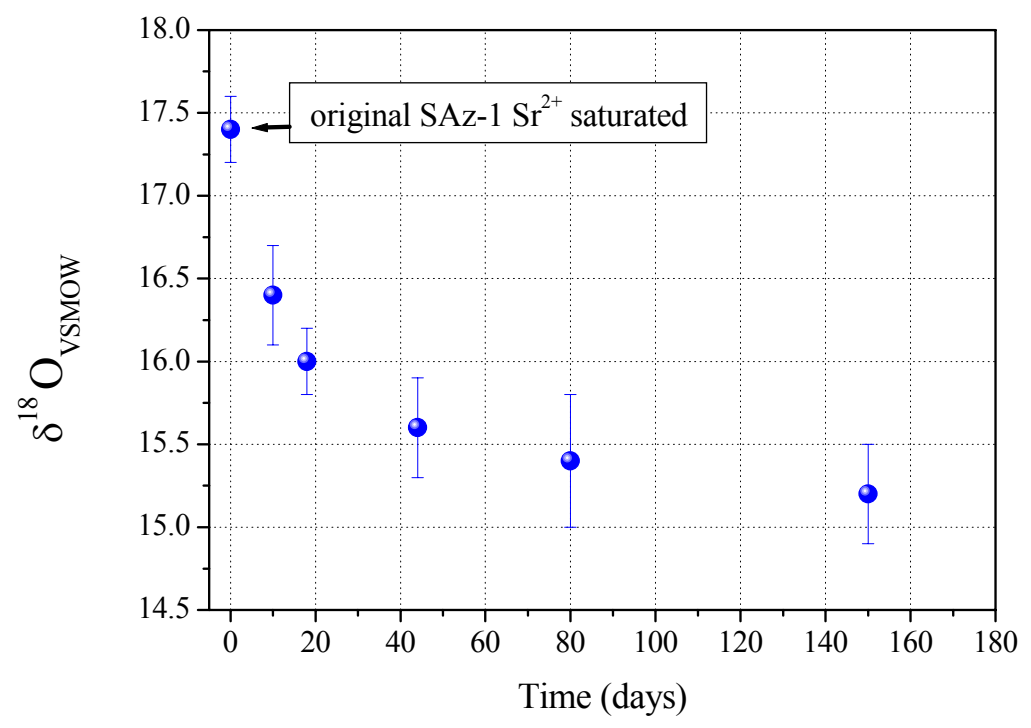

Figure 8 Plot of the evolution of the $\delta^{18} \mathrm{O}$ VSMOW ) values as a function of reaction time. Error bars correspond to the standard deviation of triplicates. 